\title{
Comprehensive rehabilitation course in adult hemiplegia: evaluation value, the PMIC
}

M locco

\author{
From de Senectute: Age and Health Forum \\ Catanzaro, Italy. 5-7 December 2009
}

Rehabilitation has a threefold problem regarding hemiplegia: the first is how to handle the single case to obtain the best result; second is to have a set of structures that allows follow up for the hemiplegic person in the whole rehabilitative course, step by step, phase by phase, according to his needs; third is to verify the reality of rehabilitative intervention.

To face the first and the second problem, post-acute clinic, intensive or extensive, outpatients departments, and the possibility "in-home" treatments are needed. A web of structures of different types is needed, working one after the other to avoid that "therapeutic lack" which causes more damage than the pathological event itself, or the advantages of hard rehabilitative work, for the patient, his family and the rehabilitative team, disappears.

For this reason, knowing if, when, where to start, to continue or to stop a rehabilitative course is extremely important and this can only be realized through a valid way of evaluation supporting scientific knowledge and clinic experience.

In the acute phase, a correct evaluation allows the definition of the best prognosis, the choice of the possible outcomes and the best setting in which to reach them. In the same way, the evaluation skill will enable the decision of when, where and how to continue the rehabilitative intervention or if consider it ended.

To face the third problem, an appropriate system of scales on which a series of evaluations can be founded is needed.

We all know that and so we use a scientific validated system of evaluation.

PMIC, proposed by SIMFER first and then accepted and proposed to its member by SIRN also, comes in

University Magna Graecia of Catanzaro, Italy this context with a particular value: to offer an identical basic evaluation protocol to all the users.

This protocol, studied with scientific accuracy, is divided in three sections as the three phases of evolution of the problem: acute phase (utilized during the hospital period in acute departments); confinement rehabilitative phase; territorial rehabilitative phase.

Knowing this population data could allow a more correct setting with no waste; plus it could allow the evaluation of the real efficacy of rehabilitative interventions and the real need of a social rehabilitative intervention on the residual impairment.

Working group SIMFER-SIRN on PMIC in Calabria has a good experience on this protocol.

Published: 19 May 2010

doi:10.1186/1471-2318-10-S1-L64

Cite this article as: locco: Comprehensive rehabilitation course in adult hemiplegia: evaluation value, the PMIC. BMC Geriatrics 2010 10(Suppl 1): L64.

Submit your next manuscript to BioMed Central and take full advantage of:

- Convenient online submission

- Thorough peer review

- No space constraints or color figure charges

- Immediate publication on acceptance

- Inclusion in PubMed, CAS, Scopus and Google Scholar

- Research which is freely available for redistribution

Submit your manuscript at www biomedcentral.com/submit 